Pacific Journal of Mathematic 


\title{
ON CONTRACTIVE SEMIGROUPS OF MAPPINGS
}

\author{
R. D. Holmes
}

The definitions of certain contraction conditions used by a number of authors (D. F. Bailey, V. M. Sehgal, M. Edelstein, and the author) on single mappings and their iterates are extended to commutative semigroups of mappings. A number of results are derived concerning fixed and periodic points which generalize those of the single mapping case.

Let $(X, d)$ be a metric space and $f$ a continuous mapping of $X$ into itself. Several authors have considered contractive conditions on $f$ in which one or more iterates of $f$ are required to "contract" certain pairs of points. Such a condition, introduced by D. F. Bailey [1] and utilized to obtain results on fixed and periodic points when $X$ is compact, requires that, for each pair of points, there is an iterate which contracts them. V. M. Sehgal [5] considered a stronger variation of this in a complete space. A further example is that introduced by the author in [3], namely that, for each pair of points, there is a point beyond which all iterates are contractive.

In each of these cases, the condition can be considered as one on the elements of the semigroup generated by $f$ (conditions on $f$ can of course be regarded as such). In this paper we extend the definitions to include arbitrary commutative semigroups of mappings and are able to obtain corresponding results. Thus the results of [1], [3], and [5] are generalized as well as results of M. Edelstein [2].

2. Definitions \& notation. Throughout, $G$ will denote a commutative semigroup (under composition) of continuous self-mappings of $X$ which contains the identity mapping (the inclusion of the identity is for convenience only and does not effect the definitions or results).

$G$ will be said to be proximally contractive (E-locally proximally contractive) if

$$
\begin{aligned}
\forall x, y \in X, x \neq y(\text { with } d(x, y)<\varepsilon) \exists g \in G & \text { such that } \\
& d(g(x), g(y))<d(x, y) .
\end{aligned}
$$

$G$ is called asymptotically contractive ( $\varepsilon$-locally asymptotically contractive) if

$$
\begin{aligned}
\forall x, y \in X, x \neq y(\text { with } d(x, y)<\varepsilon) \exists g \in G \text { such that } \\
\qquad f \in G, d(f g(x), f g(y))<d(x, y) .
\end{aligned}
$$

If (2.1) respectively (2.2) holds with $<d(x, y)$ replaced by $\leqq \lambda d(x, y)$ 
where $0<\lambda<1$, then we say that $G$ is a proximal contraction (E-local proximal contraction, etc.).

$G^{n}=\left\{g^{n} \mid g \in G\right\}$ will denote the sub-semigroup of $G$ consisting of all $n$th powers. $A$ point $z \in X$ is called a fixed (periodic) point of $G$ if, for all $g \in G\left(g \in G^{N}\right)$ we have $g(z)=z$. In the case of a periodic point, $N$ is called the period of $z$. A point $z$ is a quasi-periodic point of $G$ if, for each $g \in G$, there is a $g^{*} \in G$ with $g^{*} g(z)=z$.

In the case that $G$ is generated by a single mapping $f,(2.1)$ reduces to condition (5) (respectively (6)) of [1]. Under these circumstances, fixed or periodic points of $G$ are simply fixed or respectively periodic points of the mapping $f$. If $f$ is the sole generator of $G$ a quasi-periodic point of $G$ is just a periodic point of $f$.

Two points $x, y \in X$ are said to be $\varepsilon$-proximal (with respect to $G$ ) if, for every $\mu>0$ and $f \in G$ with $d(f(x), f(y))<\varepsilon$, there is a $g \in G$ for which $d(g f(x), g f(y))<\mu$. If $x$ and $y$ are $\varepsilon$-proximal for all $\varepsilon>0$, then they are said to be proximal.

Again, this definition coincides with the corresponding one of [2] when $G=\left\{f^{n} \mid n=1,2,3, \cdots\right\}$.

3. Results. Our first result is a generalization of Theorems 1 and 2 of Bailey [1]. We precede this by a lemma corresponding to those of [1].

Lemma 1. If $X$ is compact and, for some $x \in X, f \in G, d(x, f(x))<\varepsilon$ and $x$ and $f(x)$ are e-proximal, then $f$ has a fixed point in $X$.

Proof. Suppose $d(x, f(x))<\varepsilon$ and that $x$ and $f(x)$ are $\varepsilon$-proximal. Choose, for each $n=1,2,3, \cdots$, a $g_{n}$ such that $d\left(g_{n}(x), g_{n} f(x)\right)<1 / n$. By compactness, there is a subsequence $\left\{g_{n_{i}}\right\}$ of $\left\{g_{n}\right\}$ such that $\left\{g_{n_{i}}(x)\right\}$ converges to a point $z$, and $\left\{g_{n_{i}} f(x)\right\}$ converges to a point $w$. Clearly $z=w$, and, by continuity and commutativity, $f(z)=z$ as required.

THEOREM 1. If $X$ is compact and $G$ is proximally contractive (E-locally proximally contractive) then each pair of points in $X$ is proximal ( $\varepsilon$-proximal).

Proof. Assume, for a contradiction, that there is an $\varepsilon>0$ such that $x, y \in X$ are not $\varepsilon$-proximal. Then, there is an $f \in G$ for which

$$
\mu=\inf _{g \in G}\{d(g f(x), g f(y)\}>0 \text { and } d(f(x), f(y))<\varepsilon .
$$

Note that $f(x)$ and $f(y)$ cannot be $\varepsilon$-proximal. Let $\mu<r<\varepsilon$ be fixed and pick $g_{1}$ so that

$$
\mu \leqq d\left(g_{1} f(x), g_{1} f(y)\right)<\min \left\{\left(1+\frac{1}{2}\right) \mu, r\right\} .
$$


Then $\mu_{1}=\inf _{g \in G}\left\{d\left(g g_{1} f(x), g g_{1} f(y)\right)\right\} \geqq \mu$ and $\mu_{1}<r, \mu_{1}<\left(1+\frac{1}{2}\right) \mu$. Continuing inductively, assume that $\mu_{1}, \mu_{2}, \cdots, \mu_{n}$ and $g_{1}, g_{2}, \cdots, g_{n}$ have been defined with:

(a) $\mu_{i} \leqq \mu_{i+1}<r, i=1,2, \cdots, n-1$.

(b) $\mu_{i}=\inf _{g \in G}\left\{d\left(g g_{i} g_{i-1} \cdots g_{1} f(x), g g_{i} g_{i-1} \cdots g_{1} f(y)\right)\right\}$, $i=1,2, \cdots, n$.

(c) $\mu_{i+1}<\left(1+\frac{1}{2^{i+1}}\right) \mu_{i}, i=1,2, \cdots, n-1$.

We now choose $g_{n+1} \in G$ such that

$$
\mu_{n} \leqq d\left(g_{n+1} g_{n} \cdots g_{1} f(x), g_{n+1} g_{n} \cdots g_{1} f(y)\right)<\min \left\{\left(1+\frac{1}{2^{n+1}}\right) \mu_{n}, r\right\}
$$

and set $\mu_{n+1}=\inf _{g \in G}\left\{d\left(g g_{n+1} \cdots g_{1} f(x), g g_{n+1} \cdots g_{1} f(y)\right)\right\}$. Clearly, (a), (b), and (c) are satisfied by $g_{n+1}$ and $\mu_{n+1}$.

This defines a sequence $\left\{g_{1} f(x), g_{2} g_{1} f(x), g_{3} g_{2} g_{1} f(x), \cdots\right\}$ and, by compactness, there is a subsequence of the positive integers $\left\{n_{i}\right\}$ for which

$$
\begin{aligned}
\lim _{i \rightarrow \infty} g_{n_{\imath}} g_{n_{2}-1} \cdots g_{1} f(x) & =z \in X, \lim _{i \rightarrow \infty} g_{n_{i}} g_{n_{i}-1} \cdots g_{1} f(y) \\
& =w \in X, \text { and } \lim _{i \rightarrow \infty} \mu_{n_{i}}=\mu_{0} \geqq \mu .
\end{aligned}
$$

By the above,

$$
\begin{aligned}
\frac{\mu_{n_{i}}}{\left(1+\frac{1}{2^{n_{i}}}\right)} \leqq & \mu_{n_{i}-1} \\
& \leqq d\left(g_{n_{i}} g_{n_{i}-1} \cdots g_{1} f(x), g_{n_{i}} g_{n_{i}-1} \cdots g_{1} f(y)\right) \\
& <\left(1+\frac{1}{2^{n_{i}}}\right) \mu_{n_{i}-1} \leqq\left(1+\frac{1}{2^{n_{i}}}\right) \mu_{n_{i}}
\end{aligned}
$$

and, taking the limits as $i \rightarrow \infty, d(z, w)=\mu_{0}<\varepsilon$. Consider $d(g(z)$, $g(w))$ for a fixed $g \in G$. Then

$$
\begin{aligned}
d(z, w) & =\mu_{0}=\lim _{i \rightarrow \infty} \mu_{n_{i}} \\
& \leqq \lim _{i \rightarrow \infty} d\left(g g_{n_{\imath}} g_{n_{\imath}-1} \cdots g_{1} f(x), g g_{n_{i}} \cdots g_{1} f(y)\right) \quad \text { by }(b) \\
& =d(g(z), g(w)) .
\end{aligned}
$$

This contradicts the fact that $G$ is proximally contractive ( $\varepsilon$-locally proximally contractive) at $z$ and $w$, and the theorem is established.

CoRollary 1. If $X$ is compact and $G$ is proximally contractive, then $G$ has a unique fixed point in $X$.

Proof. Let $f$ be an arbitrary element of $G$. Then, by Theorem 
$1, x$ and $f(x)$ are proximal and, by Lemma $1, f$ has a fixed point in $X$. We now show, by induction, that any finite subset of $G$ has a common fixed point. Suppose $f_{1}(z)=f_{2}(z)=\cdots=f_{n}(z)=z$ and let $f$ be an arbitrary element of $G$. Then, as $z$ and $f(z)$ are proximal, Lemma 1 gives us a sequence $\left\{g_{i}\right\} \subseteq G$ such that $w=\lim _{i \rightarrow \infty} g_{i}(z)$ is a fixed point of $f$. But then, for $k=1,2, \cdots, n, f_{k}(w)=\lim _{i \rightarrow \infty} f_{k} g_{i}(z)=$ $\lim _{i \rightarrow \infty} g_{i} f_{k}(z)=\lim _{i \rightarrow \infty} g_{i}(z)=w$ and $w$ is a common fixed point of $f, f_{1}, f_{2}, \cdots, f_{n}$. Thus, as the set of fixed points of an element of $G$ is closed, compactness insures at least one fixed point of $G$. Clearly such a point is unique.

CoROllary 2. If $X$ is compact and $G$ is e-locally proximally contractive then $G$ has periodic points all with common period $N$.

Proof. As $X$ is compact, it has a finite cover by sets of diameter less that $\varepsilon$ containing, say, $k$ members. Let $N$ be any common multiple of $1,2, \cdots, k$, and let $f \in G$ and consider $x, f(x), f^{2}(x), \cdots, f^{k}(x)$. At least two of these must lie in one member of the cover, giving us a point $y$ such that $d\left(y, f^{p}(y)\right)<\varepsilon$ where $1 \leqq p \leqq k$. By Theorem $1, y$ and $f^{p}(y)$ are $\varepsilon$-proximal and Lemma 1 implies that there is a point $z \in X$ with $f^{p}(z)=z$. Thus, as $p \mid N, f^{N}(z)=z$. The same argument as in the proof of Corollary 1 will show that, for any finite subset $\left\{f_{1}^{N}, f_{2}^{N}, \cdots, f_{n}^{N}\right\}$ of $G^{N}$, there is a $w$ with $f_{i}^{N}(w)=w, i=1, \cdots, n$. Hence, compactness again gives us a point of period $N$ under $G$.

Theorem 1 and its corollaries generalize Theorems 1 and 2 of [1] and their corollaries, while Corollary 2 is a generalization of Theorem 2 of [3].

We next consider asymptotically contractive semigroups on not necessarily compact spaces. An additional hypothesis, (3.1), is used which reduces to condition 1.2 of [2] whenever $G$ is generated by a single element.

THeOREM 2. If $G$ is asymptotically contractive on $(X, d)$ and, in addition

$$
\exists x, z \in X \text { such that } \forall \varepsilon>0, f \in G, \exists g \in g \text { for which }
$$

$$
d(g f(x), z)<\varepsilon,
$$

then $z$ is the unique fixed point of $G$.

Proof. Let $x, z$ be as in (3.1) and consider, for a fixed element $l \in G$,

$$
\sigma_{1}=\inf _{g \in G}\{d(g(x), g l(x))\} \geqq 0
$$


We distinguish two cases:

Case 1. $\sigma_{1}=0$.

For each $n=1,2,3, \cdots$ let $g_{n} \in G$ be such that

$$
\mathrm{d}\left(g_{n}(x), g_{n} l(x)\right)<1 / 2^{n} .
$$

As $G$ is asymptotically contractive, there is, for each $n$, an $f_{n} \in G$ such that $d\left(g f_{n} g_{n}(x), g f_{n} g_{n} l(x)\right)<d\left(g_{n}(x), g_{n} l(x)\right)$ for all $g \in G$. By (3.1), there is an $h_{n} \in G$ for which

$$
d\left(h_{n} f_{n} g_{n}(x), z\right)<1 / 2^{n} .
$$

Thus

$$
\begin{aligned}
d\left(h_{n} f_{n} g_{n} l(x), z\right) \leqq & d\left(h_{n} f_{n} g_{n} l(x), h_{n} f_{n} g_{n}(x)\right)+d\left(h_{n} f_{n} g_{n}(x), z\right) \\
& <1 / 2^{n}+1 / 2^{n}=1 / 2^{n-1} .
\end{aligned}
$$

From (3.2) and (3.3) we have

$$
z=\lim _{n \rightarrow \infty} h_{n} f_{n} g_{n} l(x)=\lim _{n \rightarrow \infty} l h_{n} f_{n} g_{n}(x)=l(z),
$$

and $z$ is a fixed point of $l$.

Case 2. $\sigma_{1}>0$.

We show that this case cannot arize by reaching a contradiction. Let $b>\sigma_{1}$ and $g_{1} \in G$ be such that $d\left(g_{1}(x), g_{1} l(x)\right)<\min \left\{b,\left(1+\frac{1}{2}\right) \sigma_{1}\right\}$. Now, there is an $f_{1} \in G$ such that $d\left(g f_{1} g_{1}(x), g f_{1} g_{1} l(x)\right)<d\left(g_{1}(x), g_{1} l(x)\right)$ for all $g \in G$. By (3.1) there is an $h_{1} \in G$ with $d\left(h_{1} f_{1} g_{1}(x), z\right)<\frac{1}{2}$. Set $x_{1}=h_{1} f_{1} g_{1}(x)$ and $\sigma_{2}=\inf _{g \in G} d\left(g\left(x_{1}\right), g l\left(x_{1}\right)\right)$. Note that $0<\sigma_{1} \leqq \sigma_{2}<\min$ $\left\{b,\left(1+\frac{1}{2}\right) \sigma_{1}\right\}$.

To continue by induction, suppose that $x_{n-1}$ and

$$
\sigma_{n}=\inf _{g \in G} d\left(g\left(x_{n-1}\right), g l\left(x_{n-1}\right)\right)<\min \left\{b,\left(1+\frac{1}{2^{n-1}}\right) \sigma_{n-1}\right\}
$$

have been defined. Then there is a $g_{n} \in G$ with

$$
d\left(g_{n}\left(x_{n-1}\right), g_{n} l\left(x_{n-1}\right)\right)<\min \left\{b,\left(1+\frac{1}{2^{n}}\right) \sigma_{n}\right\} .
$$

Similarly, there is an $f_{n} \in G$ and $h_{n} \in G$ such that

$$
d\left(g f_{n} g_{n}\left(x_{n-1}\right), g f_{n} g_{n} l\left(x_{n-1}\right)\right)<d\left(g_{n}\left(x_{n-1}\right), g_{n} l\left(x_{n-1}\right)\right)
$$

for all $g \in G$ and $d\left(h_{n} f_{n} g_{n}\left(x_{n-1}\right), z\right)<1 / 2^{n}$. We can set $x_{n}=h_{n} f_{n} g_{n}\left(x_{n-1}\right)$ and $\sigma_{n+1}=\inf _{g \in G} d\left(g\left(x_{n}\right), g l\left(x_{n}\right)\right)$ and we have

$$
\sigma_{n} \leqq \sigma_{n+1}<\min \left\{b,\left(1+\frac{1}{2^{n}}\right) \sigma_{n}\right\}
$$


Now, as $\left\{\sigma_{n}\right\}$ is a bounded monotone sequence of real numbers, there is a $\sigma_{0}>0$ with $\lim _{n \rightarrow \infty} \sigma_{n}=\sigma_{0}$. Clearly, $\lim _{n \rightarrow \infty} x_{n}=z$ and $\lim _{n \rightarrow \infty} l\left(x_{n}\right)=l(z)$ and thus $\sigma_{0}=d(z, l(z))$. But then

$$
d(g(z), g l(z))=\lim _{n \rightarrow \infty} d\left(g\left(x_{n}\right), g l\left(x_{n}\right)\right) \geqq \lim _{n \rightarrow \infty} \sigma_{n+1}=\sigma_{0}=d(z, l(z))
$$

contradicting the fact that $G$ is asymptotically contractive at $z$ and $l(z)$.

Thus, Case 1 must always hold and $z$ is a fixed point for each element of $G$. Clearly, it is the only point with this property.

If $G$ consists of the identity together with the iterates of a single contractive mapping, then $G$ is asymptotically contractive. A less trivial example is given below in which neither of the two generators of $G$ is locally contractive.

Example 1. Let $X$ be the interval $[0,18]$ (in the usual metric) and define $f$ and $g$ as follows:

$$
\begin{gathered}
f(x)= \begin{cases}x / 2, & x \in[0,6] \\
3, & x \in[6,12] \\
\frac{3 x}{2}-15, & x \in[12,18]\end{cases} \\
g(x)= \begin{cases}x, & x \in[0,6] \\
2 x-6, & x \in[6,9] \\
12, & x \in[9,12] \\
x, & x \in[12,14] \\
2 x-14, & x \in[14,16] \\
18, & x \in[16,18] .\end{cases}
\end{gathered}
$$

Straightforward calculation shows that

$$
f g(x)=g f(x)= \begin{cases}x / 2, & x \in[0,6] \\ 3, & x \in[6,12] \\ \frac{3 x}{2}-15, & x \in[12,14] \\ 3 x-36, & x \in[14,16] \\ 12, & x \in[16,18] .\end{cases}
$$

Thus we can let $G$ be the semigroup generated by $f$ and $g$. That $G$ is asymptotically contractive can be seen by noting that $f^{2}$ is a $\frac{3}{4}$-contraction and that $g$ is the identity on the range of $f^{2}$. This same remark implies that (3.1) is satisfied for any $x \in X$ and for $z=0$. 
Theorem 2 generalizes both Theorem 1 of [2] and Theorem 3 of [3]. For a local version of Theorem 2 we have:

THEOREM 3. If $G$ is e-locally asymptotically contractive on $(X, d)$ and (3.1) is satisfied, then $z$ is a quasi-periodic point of $G$.

Proof. We can apply (3.1) to get a $g \in G$ with $d(g(x), z)<\varepsilon / 2$. Applying (3.1) again to $l g(x)$, we get an $l^{*} \in G$ such that $d\left(l^{*} l g(x)\right.$, $z)<\varepsilon / 2$. If we set $y=g(x)$, then it is clear that $y$ and $z$ also satisfy (3.1) and $d(y, l * l(y)) \leqq d(y, z)+d(l * l(y), z)<\varepsilon / 2+\varepsilon / 2=\varepsilon$. If we now apply the proof of Theorem 2 (setting $b=\varepsilon$ ) we get $l * l(z)=z$. As $l \in G$ is arbitrary, it follows that $z$ is an almost periodic point as required.

Theorems 2 of [2] and 4 of [3] are generalized by Theorem 3 . In order to guarantee a fixed point in the local case one must add more conditions. That $\varepsilon$-chainability alone is insufficient is shown by Example 2 of [2]. It is sufficient, however, to assume, together with $\varepsilon$-chainability, that $z$ has a compact spherical neighborhood of radius $\varepsilon$ (see [2] for the motivation for this condition).

THEOREM 4. If, in addition to the conditions of Theorem 3, $X$ is $\varepsilon$-chainable and $z$ has a compact spherical neighborhood of radius $\varepsilon$, then $z$ is the unique fixed point of $G$.

Proof. We suppose, for a contradiction, that there is an $l \in G$ for which $l(z) \neq z$. Let $k$ be the smallest integer for which there is an $\varepsilon$-chain $\sigma=\left\{z=x_{0}, x_{1}, \cdots, x_{k}=l(z)\right\}$ from $z$ to $l(z)$ and suppose $\sigma$ is a chain with $k$ links.

We construct a subset $T$ of $G$ as follows:

$$
\begin{aligned}
T & =\left\{g \in G \mid g(z)=z, d\left(f g\left(x_{i}\right), f g\left(x_{i-1}\right)\right)\right. \\
& \left.<d\left(x_{i}, x_{i-1}\right), i=1,2, \cdots, k, f \in G\right\} .
\end{aligned}
$$

Note that $T$ is nonempty, for, as $G$ is $\varepsilon$-locally asymptotically contractive, there is, for each $i, i=1,2, \cdots, k$, an $f_{i} \in G$ with $d\left(g f_{i}\left(x_{i}\right), g f_{i}\left(x_{i-1}\right)\right)<d\left(x_{i}, x_{i-1}\right), g \in G$. Set $f_{0}=f_{1} f_{2} \cdots f_{k}$. Then, by Theorem 3 , there is an $f_{0}^{*}$ such that $f_{0}^{*} f_{0}(z)=z$. Also

$$
\begin{aligned}
& d\left(f_{0}^{*} f_{0}\left(x_{i}\right), f_{0}^{*} f_{0}\left(x_{i-1}\right)\right) \\
& \quad=d\left(f_{0}^{*} f_{1} f_{2} \cdots f_{i-1} f_{i+1} \cdots f_{k} f_{i}\left(x_{i}\right), f_{0}^{*} f_{1} \cdots f_{i-1} f_{i+1} \cdots f_{k} f_{i}\left(x_{i-1}\right)\right) \\
& \quad<d\left(x_{i}, x_{i-1}\right)<\varepsilon \text { and } f_{0}^{*} f_{0} \in T .
\end{aligned}
$$

Set $r(x)=\inf \{d(z, f(x)) \mid f \in T\}$. Then $r(x)$ is continuous on $X$ and, if $d(z, x)<\varepsilon, \quad 0 \leqq r(x)<d(z, x)$. Set $\delta=\frac{1}{2}\left(\varepsilon-d\left(x_{1}, x_{2}\right)\right)$ and 
$C=\left\{x \in X \mid \delta \leqq d(z, x) \leqq d\left(z, x_{1}\right)\right\}$. Then $C$ is compact and $x_{1} \in C$, for, if $d\left(z, x_{1}\right)<\delta$ then

$$
\begin{aligned}
d\left(z, x_{2}\right) \leqq & d\left(z, x_{1}\right)+d\left(x_{1}, x_{2}\right) \\
& <\delta+d\left(x_{1}, x_{2}\right) \\
& =\frac{1}{2} \varepsilon+\frac{1}{2} d\left(x_{1}, x_{2}\right)<\varepsilon
\end{aligned}
$$

and $\left\{z, x_{2}, x_{3}, \cdots, x_{k}\right\}$ is an $\varepsilon$-chain from $z$ to $l(z)$ with fewer than $k$ links. The function $r(x) / d(z, x)$ is continuous on $C$ and hence assumes a maximum $\gamma<1$ on $C$. If $\gamma<\alpha<1$, then, by the definition of $r$, for each $x \in C$, there is an $f_{x} \in T$ such that $d\left(z, f_{x}(x)\right)<\alpha d(z, x)$.

Consider the chain $\sigma_{1}=\left\{z=f_{x_{1}}\left(x_{0}\right), f_{x_{1}}\left(x_{1}\right), \cdots, f_{x_{1}}\left(x_{k}\right)=l(z)\right\}$. As $f_{x_{1}} \in T,\left(f_{x_{1}}\left(x_{i}\right), f_{x_{1}}\left(x_{i-1}\right)\right)<d\left(x_{i}, x_{i-1}\right)$ and, if we had $d\left(z, f_{x_{1}}\left(x_{1}\right)\right)<\delta$, we would have, as above,

$$
d\left(z, f_{x_{1}}\left(x_{2}\right)\right) \leqq d\left(z, f_{x_{1}}\left(x_{1}\right)\right)+d\left(f_{x_{1}}\left(x_{1}\right), f_{x_{1}}\left(x_{2}\right)\right)<\delta+d\left(x_{1}, x_{2}\right)<\varepsilon
$$

contrary to the minimality of $k$. Thus $f_{x_{1}}\left(x_{1}\right) \in C$.

We can now apply the above reasoning to $x_{1}^{\prime}=f_{x_{1}}\left(x_{1}\right)$ and $\sigma_{1}$. As $f_{x_{1}^{\prime}} f_{x_{1}} \in T$, we thus generate a new chain $\sigma_{2}$ with $x_{1}^{2} \in C$ and $d\left(z, x_{1}^{2}\right)<$ $\alpha d\left(z, x_{1}^{\prime}\right)<\alpha^{2} d\left(z, x_{1}\right)<\alpha^{2} \varepsilon$.

We can clearly continue this process, constructing $\sigma_{n}$ and $x_{1}^{n}$ with $d\left(z, x_{1}^{n}\right)<\alpha^{n} d\left(z, x_{1}\right)$ and $x_{1}^{n} \in C$. But this is a contradiction, for $x_{1}^{n} \in C$ implies $d\left(z, x_{1}^{n}\right) \geqq \delta>0$ or $0<\delta<\alpha^{n} \varepsilon$ for each $n$. The desired conclusion now follows.

Theorem 4, while it does generalize Theorem 3 of [2], fails to do so for the corresponding Theorem 5 of [3] due to the extra condition requiring a compact neighborhood of $z$. For the somewhat stronger $\varepsilon$-local asymptotic contraction this defect is no longer present as shown by the corollary to our next theorem.

THEOREM 5. If $G$ is an E-local asymptotic contraction on $(X, d)$ and $X$ is e-chainable, then there is a metric $D$ on $X$, topologically equivalent to $d$, such that $G$ is an asymptotic contraction on $(X, D)$.

Proof. We define $D$ on $X$ by setting

$$
\begin{aligned}
D(x, y) & =\inf \left\{\sum_{i=1}^{k} d\left(x_{i}, x_{i-1}\right) \mid x_{i} \in X, x_{0}=x, x_{k}\right. \\
& \left.=y, d\left(x_{i}, x_{i-1}\right)<\varepsilon, i=1,2, \cdots, k\right\} .
\end{aligned}
$$

Thus $D(x, y)$ is the infimum of the lengths of all $\varepsilon$-chains from $x$ to $y$. This is easily shown to be a metric equivalent to $d$ (cf. e.g. [4]).

Let $x, y \in X$ be fixed and let $0<\rho \leqq(1-\lambda) / 2 D(x, y)$. Now, by the definition of $D(x, y)$, there is an $\varepsilon$-chain $\left\{x=x_{0}, x_{1}, \cdots, x_{k}=y\right\}$ from $x$ to $y$ such that $\lambda D(x, y)+\rho \geqq \sum_{i=1}^{k} \lambda d\left(x_{i}, x_{i-1}\right)$. For each 
$i=1,2, \cdots, k$ we have $d\left(x_{i}, x_{i-1}\right)<\varepsilon$ and thus there is an $f_{i} \in G$ for which $d\left(g f_{i}\left(x_{i}\right), g f_{i}\left(x_{i-1}\right)\right) \leqq \lambda d\left(x_{i}, x_{i-1}\right)<\varepsilon$ for all $g \in G$.

If we now set $f=f_{1} f_{2} \cdots f_{k} \in G$ we have $d\left(g f\left(x_{i}\right), g f\left(x_{i-1}\right)\right) \leqq$ $\lambda d\left(x_{i}, x_{i-1}\right)<\varepsilon, i=1,2, \cdots, k, g \in G$. Hence $\left\{g f\left(x_{0}\right), g f\left(x_{1}\right), \cdots, g f\left(x_{k}\right)\right\}$ is an $\varepsilon$-chain from $g f(x)$ to $g f(y)$ and

$$
\begin{aligned}
\sum_{i=1}^{k} \lambda d\left(x_{i}, x_{i-1}\right) & \geqq \sum_{i=1}^{k} d\left(g f\left(x_{i}\right), g f\left(x_{i-1}\right)\right. \\
& \geqq D(g f(x), g f(y)) .
\end{aligned}
$$

Thus, if we set $\tilde{\lambda}=(1+\lambda) / 2<1$, we have

$$
\tilde{\lambda} D(x, y)=\lambda D(x, y)+\frac{1-\lambda}{2} D(x, y) \geqq \lambda D(x, y)+o \geqq D(g f(x), g f(y))
$$

for all $g \in G$.

Thus $G$ is an asymptotic contraction on $(X, D)$ as required.

Corollary. If $G$ is an s-local asymptotic contraction on $(X, d), X$ is e-chainable, and condition (3.1) is satisfied, then $G$ has a unique fixed point in $X$.

Proof. Applying Theorem 5 we get the metric $D$ with respect to which $G$ is an asymptotic contraction. From the construction of $D$, we can see that $D(x, y)<\varepsilon$ implies $d(x, y)=D(x, y)$ and so (3.1) is satisfied for $(X, D)$ by the same pair of points $x$ and $z$. As an asymptotic contraction is, afortiori, asymptotically contractive, we can now apply Theorem 2 to obtain the desired conclusion.

\section{REFERENCES}

1. D. F. Bailey, Some theorems on contractive mappings, J. London Math. Soc., 41 (1966), 101-106.

2. M. Edelstein, On fixed and periodic points under contractive mappings, J. London Math. Soc., 37 (1962), 74-79.

3. R. D. Holmes, On fixed and periodic points under certain sets of mappings, Canad. Math. Bull., 12 (1969), 813-822.

4. P. R. Meyers, Some extensions of Banach's contraction theorem, J. Res. NBS, 69B (1965), 179-184.

5. V. M. Sehgal, A fixed point theorem for local contraction mappings, Notices Amer. Math. Soc., 12 (1965), 461.

Received November 25, 1970. The material of this paper is part of the author's doctoral dissertation at Dalhousie University.

University of Alberta 



\title{
PACIFIC JOURNAL OF MATHEMATICS
}

\author{
EDITORS
}

\author{
H. SAMelson \\ Stanford University \\ Stanford, California 94305 \\ C. R. HoBBy \\ University of Washington \\ Seattle, Washington 98105
}

J. DugunduI

Department of Mathematics

University of Southern California

Los Angeles, California 90007

RICHARD ARENS

University of California

Los Angeles, California 90024

\section{ASSOCIATE EDITORS}

\author{
E. F. BeCKENBACH
}

B. H. NEUMANN

F. WoLF

K. YOSHIDA

\section{SUPPORTING INSTITUTIONS}

\author{
UNIVERSITY OF BRITISH COLUMBIA \\ CALIFORNIA INSTITUTE OF TECHNOLOGY \\ UNIVERSITY OF CALIFORNIA \\ MONTANA STATE UNIVERSITY \\ UNIVERSITY OF NEVADA \\ NEW MEXICO STATE UNIVERSITY \\ OREGON STATE UNIVERSITY \\ UNIVERSITY OF OREGON \\ OSAKA UNIVERSITY \\ UNIVERSITY OF SOUTHERN CALIFORNIA
}

\author{
STANFORD UNIVERSITY \\ UNIVERSITY OF TOKYO \\ UNIVERSITY OF UTAH \\ WASHINGTON STATE UNIVERSITY \\ UNIVERSITY OF WASHINGTON \\ AMERICAN MATHEMATICAL SOCIETY \\ CHEVRON RESEARCH CORPORATION \\ NAVAL WEAPONS CENTER
}

The Supporting Institutions listed above contribute to the cost of publication of this Journal, but they are not owners or publishers and have no responsibility for its content or policies.

Mathematical papers intended for publication in the Pacific Journal of Mathematics should be in typed form or offset-reproduced, (not dittoed), double spaced with large margins. Underline Greek letters in red, German in green, and script in blue. The first paragraph or two must be capable of being used separately as a synopsis of the entire paper. The editorial "we" must not be used in the synopsis, and items of the bibliography should not be cited there unless absolutely necessary, in which case they must be identified by author and Journal, rather than by item number. Manuscripts, in duplicate if possible, may be sent to any one of the four editors. Please classify according to the scheme of Math. Rev. Index to Vol. 39. All other communications to the editors should be addressed to the managing editor, Richard Arens, University of California, Los Angeles, California, 90024.

50 reprints are provided free for each article; additional copies may be obtained at cost in multiples of 50 .

The Pacific Journal of Mathematics is published monthly. Effective with Volume 16 the price per volume (3 numbers) is $\$ 8.00$; single issues, $\$ 3.00$. Special price for current issues to individual faculty members of supporting institutions and to individual members of the American Mathematical Society: $\$ 4.00$ per volume; single issues $\$ 1.50$. Back numbers are available.

Subscriptions, orders for back numbers, and changes of address should be sent to Pacific Journal of Mathematics, 103 Highland Boulevard, Berkeley, California, 94708.

PUBLISHED BY PACIFIC JOURNAL OF MATHEMATICS, A NON-PROFIT CORPORATION

Printed at Kokusai Bunken Insatsusha (International Academic Printing Co., Ltd.), 7-17, Fujimi 2-chome, Chiyoda-ku, Tokyo, Japan. 


\section{Pacific Journal of Mathematics}

\section{Vol. 37, No. $3 \quad$ March, 1971}

Mohammad Shafqat Ali and Marvin David Marcus, On the degree of the

minimal polynomial of a commutator operator ................ 561

Howard Anton and William J. Pervin, Integration on topological

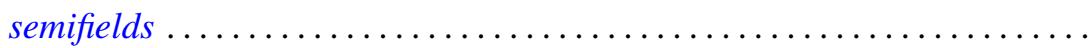

Martin Bartelt, Multipliers and operator algebras on bounded analytic

functions .................................... 575

Donald Earl Bennett, Aposyndetic properties of unicoherent continua ...... 585

James W. Bond, Lie algebras of genus one and genus two ............. 591

Mario Borelli, The cohomology of divisorial varieties ............... 617

Carlos R. Borges, How to recognize homeomorphisms and isometries ....... 625

J. C. Breckenridge, Burkill-Cesari integrals of quasi additive interval

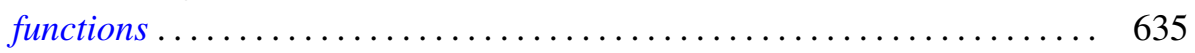

J. Csima, A class of counterexamples on permanents ................ 655

Carl Hanson Fitzgerald, Conformal mappings onto $\omega$-swirly domains . . . . . . 657

Newcomb Greenleaf, Analytic sheaves on Klein surfaces .............. 671

G. Goss and Giovanni Viglino, C-compact and functionally compact

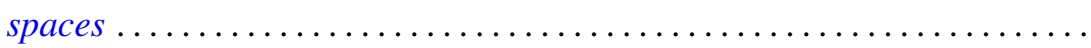

Charles Lemuel Hagopian, Arcwise connectivity of semi-aposyndetic plane

continua ..................................... 683

John Harris and Olga Higgins, Prime generators with parabolic limits ...

David Michael Henry, Stratifiable spaces, semi-stratifiable spaces, and their

relation through mappings .......................

Raymond D. Holmes, On contractive semigroups of mappings ........... 701

Joseph Edmund Kist and P. H. Maserick, BV-functions on semilattices ....... 711

Shûichirô Maeda, On point-free parallelism and Wilcox lattices ........... 725

Gary L. Musser, Linear semiprime $(p ; q)$ radicals ................. 749

William Charles Nemitz and Thomas Paul Whaley, Varieties of implicative

semilattices..................................... 759

Jaroslav Nešetřil, A congruence theorem for asymmetric trees ............ 771

Robert Anthony Nowlan, A study of $H$-spaces via left translations .......... 779

Gert Kjærgaard Pedersen, Atomic and diffuse functionals on a $C^{*}$-algebra ... 795

Tilak Raj Prabhakar, On the other set of the biorthogonal polynomials

suggested by the Laguerre polynomials...

801

Leland Edward Rogers, Mutually aposyndetic products of chainable

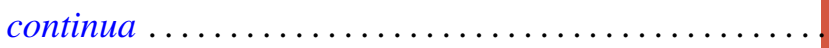

Frederick Stern, An estimate for Wiener integrals connected with squared

error in a Fourier series approximation.

Leonard Paul Sternbach, On k-shrinking and k-boundedly complete basic

sequences and quasi-reflexive spaces .................... 817

Pak-Ken Wong, Modular annihilator $A^{*}$-algebras ........ 